\title{
INDISCIPLINA NO CONTEXTO ESCOLAR: UM DIÁLOGO ENTRE ESCOLA E FAMÍLIA
}

\author{
Cláudia Cristina Santana Nascimento Araújo ${ }^{1}$
}

Resumo: O presente artigo indisciplina no contexto escolar: Um diálogo entre escola e família, seu foco para produção foi em virtude ao índice de crescimento da indisciplina nas escolas que consequentemente tem gerado grande evasão, repetência e, outros possíveis problemas em sala. Sob a ótica de professores, visou compreender como a indisciplina escolar interfere no processo de ensino-aprendizagem e a importância do trabalho de parceria entre pais, alunos e professores. Pois, acredita que essa temática afeta diretamente no processo de ensino-aprendizagem e, é por meio desse interesse de investigação que o referido estudo baseou-se em uma pesquisa qualitativa, em que procurou as concepções dos professores acerca dessa temática desenvolvida, sobretudo como eles agem e atuam frente a esses acontecimentos cotidianamente. Como procedimento de coleta de dados, foram utilizados questionários com perguntas abertas e fechadas com professores de uma escola pública de Guanambi-Bahia, no nível do ensino fundamental I, justificando que o objeto da pesquisa restringiu-se a escola pública em razão de possuir bem mais casos de indisciplina. Com isso, o estudo evidenciou que o problema da indisciplina escolar é algo estudado por diversos teóricos e, pelo que foi apresentado pelos professores em suas respostas nos questionários, ficou claro, a necessidade cada vez mais de reflexão e ação sobre este caso.

Palavras-chaves: Alunos. Educação. Ensino-aprendizagem. Família-escola. Indisciplina.

\footnotetext{
${ }^{1}$ Aluna do curso de Mestrado em ciências da educação.
} 


\section{INTRODUÇÃO}

O presente artigo "Indisciplina no contexto escolar: um diálogo entre escola e família", trata-se de um estudo realizado no intuito de contribuir com as discussões sobre a busca de ações pedagógicas e resolver o problema da indisciplina na escola. A proposta do estudo centrou na relevância da interação escola e família, formação docente para lidar com essa realidade dinâmica e desafiadora e ainda do estudo das políticas educacionais e influências do meio social com a violência.

Este tema surgiu de estudos e discussões sobre o problema da indisciplina escolar em uma escola pública municipal de Guanambi-BA. Dentro dos diferentes problemas que as escolas enfrentam na atualidade. Cabe destacar a questão da indisciplina como motivo e inquietação na escola, gerando dificuldades no processo de aprendizado, não apenas do aluno indisciplinado como dos demais educandos.

A indisciplina é um debate de uma realidade comum que tem atingido escolas brasileiras, tanto públicas como particulares, que tem colocado aos educadores os desafios de compreender as causas desse desvio de comportamento, o que ressalta a importância do estudo proposto.

Dessa forma, o estudo teve por finalidade discutir a questão da indisciplina escolar que tem sido uma realidade frequente nas escolas, sendo um dos maiores obstáculos pedagógicos. $O$ estudo foi realizado na perspectiva exploratória e qualitativa, por meio de um estudo em campo, que consistiu de início o levantamento e análise das obras dos autores que discutem a temática e em seguida a realização da entrevista com educadores.

Tanto a família quanto a escola compartilham de um objetivo comum formar os educandos para o mundo. A motivação desta pesquisa assenta-se no questionamento sobre quais são as propostas educacionais que podem contribuir para resolver o problema da indisciplina que está relacionada à desordem, no desrespeito referente a normas de conduta e à falta de limites do aluno nas relações do cotidiano escolar.

Essa é uma realidade manifestada com frequência na escola, sendo uma das maiores dificuldades pedagógicas. Buscou-se verificar as ações e intervenções para a diminuição da indisciplina e como essas subversões 
influenciam no aprendizado escolar. Por outro lado, é possível minimizar os problemas da indisciplina por meio de um trabalho de parceria entre a escola, família e sociedade.

No entanto, existem algumas dificuldades nesse caminho que estão associadas aos fatores como a falta de tempo da família para participar mais da comunidade escolar e acompanhar o desenvolvimento do filho. É um trabalho de parceria escola-família, pois ambas são responsáveis pela formação de valores morais que integram o meio social e a atuação dos cidadãos.

Assim, o estudo demonstra a necessidade de meios de intervenções tanto para alunos e pais como professores e sociedade, porque o problema da indisciplina é também social que influencia no ambiente escolar e consequentemente na formação educacional.

\section{MATERIAL E MÉTODOS}

Trata-se de uma pesquisa que buscou junto à análise das situações empíricas na sala de aula, somada ao levantamento documental e bibliográfico que tratam do tema proposto ajudando a compreender melhor esses conflitos. Buscando para o problema e servindo de auxílio a outros estudantes e profissionais da educação que convivem com essa dificuldade, na tentativa de aliviar as angústias e traumas decorrentes.

O artigo aqui desenvolvido é resultado de uma pesquisa do tipo descritiva de cunho qualitativo com enfoque a um estudo de caso associado à revisão bibliográfica e documental relacionados à questão da indisciplina no ambiente escolar.

Para isso foram utilizados vários autores que melhor contribuem para o estudo da temática no campo escolar, complementado com entrevistas semiestruturais individuais com professores da rede pública de ensino da cidade de Guanambi-BA. 


\section{RESULTADOS E DISCUSSÃO}

A indisciplina dentro do espaço escolar é um problema que atinge muitos professores e, demais profissionais da rede de educação na contemporaneidade.

Esta é então algo discutido por muitos educadores, os quais dedicam parte de seu tempo para fazer cursos formativos em relação a isso. E se justifica talvez não só pela incidência de indisciplina escolar, como também é o momento desses educadores refletirem sobre o seu papel e pensar quais seriam as disciplinas.

Segundo o dicionário produzido por Ferreira (2008) a indisciplina significa um procedimento considerado contrário à disciplina. Isso leva a entender sobre os casos em que o educando fica subordinado ao educador, uma ordem que impõe ao educando a se organizar e cumprir determinada regra.

É pertinente salientar que a indisciplina não se faz presente apenas no Brasil, ou seja, encontra-se também em outros países com culturas totalmente diferenciadas das brasileiras e, não se limita a nenhum nível de escolaridade seja da educação infantil até o ensino superior.

Ferreira (2008) ainda traz que a indisciplina pode ser algo presente em vários países, porém pode acontecer de forma diferenciada em razão de cada país ter os seus valores culturais diferenciados.

No Brasil especificamente, Aquino (2011) nos remete que a origem da indisciplina surge como tema de debate logo após os anos 90 e, quando ganhou essa atenção no campo educacional deu prosseguimento a diversos estudos sobre o caso, como também publicações em História, Serviço Social, História da Educação e Sociologia.

Nesse âmbito de originalidade, a indisciplina precisa ser pensada e estudada baseada em três fatos muito comuns a atual sociedade, isto é, na conduta dos educandos exercida nas atividades escolares tanto na escola ou fora dela.

O segundo fato aparece na socialização e relacionamentos que os educandos exercem em relação ao professor, aos colegas, família, amigos e sociedade em geral. E, o terceiro momento, trata-se do desenvolvimento 
cognitivo dos educandos, ou seja, são as demonstrações feitas pelos educandos socialmente.

Em relação às mudanças ocasionadas ao longo do século XXI, percebese que o conceito de indisciplina vem se modificando e, na maioria das vezes, o educador é quem dita às regras a serem seguidas e, como forma de colocar ordem para o exercício de sua prática pedagógica.

A (in) disciplina escolar apresenta "atualmente, expressão diferente, é mais complexa e criativa, e parece aos professores mais difícil de equacionar e resolver de um modo afetivo" (GARCIA, 1999, p. 103).

De acordo ao citado acima, o educador que não recebe uma boa formação inicial e continuada, interfere muito na sua forma de pensar sobre o caso, o qual gera no reforço da indisciplina e, também na exclusão educativa.

Ainda "na busca dos determinantes da (in) disciplina, a influência de fatores extraescolares no comportamento dos alunos, na visão de muitos educadores, parece ocupar primeiro plano" (AQUINO, 1999, p. 90).

Nessa perspectiva, o autor nos remete a pensar que as vivências externas dos educandos na sociedade pode sim interferir no contexto escolar, isto é, aquele que sofre com as desigualdades econômicas, sociais, psicológicas, pode apresentar-se enfraquecido e, assim ser um educando indisciplinar.

\begin{abstract}
Um dos causadores do enfrentamento da problemática disciplinar é que o educador não dispõe de uma concepção, de um método, de uma ferramenta eficiente. De um modo geral, está marcado pela concepção idealista: tem uma série de ideias bonitas sobre disciplina, mas não sabe por que não se consegue colocar em prática. Para isso concorre a falta de análise dos determinantes, a falta de clareza de mediações concretas, bem como a falta de interação entre estas três dimensões básicas (VASCONCELLOS, 1996, p. 17).
\end{abstract}

Através disso, fica claro, que nenhum indivíduo já nasce indisciplinado. Isso quer dizer que ela nasce e, a partir das relações sociais, econômicas que vai construir a percepção de comportamento de cada um deles.

A partir desses questionamentos sobre a sua origem epistemológica que parte de diversas opiniões, é perceptível a necessidade de ajustar o comportamento do educando na escola e sociedade também.

Em relação ao que foi apontada, a indisciplina pode sim interferir substancialmente no processo de ensino-aprendizagem do educando, como 
também na função exercida pelo educador e por isso, tem se tornado alvo para discussões nas reuniões entre pais por exemplo. Para isso, a escola não é a única responsável por disciplinar o educando.

Nesse momento, será feito um levantamento reflexivo acerca da geração e análise dos dados obtidos durante a pesquisa no município de Guanambi-Ba. Foi necessário separá-los em categorias, e para maior credibilidade dos resultados, foram feitas referências a alguns teóricos, cujas discussões corroboram com a análise dessa pesquisa. Além disso, foram apresentadas algumas falas dos sujeitos pesquisados para ratificar os dados obtidos.

Ao longo da pesquisa, os dados que foram coletados consistiram em obter várias contingências sobre a indisciplina na escola. Ao fazer a leitura geral dos questionários foi possível perceber que a temática gera muitas expectativas aos professores.

As respostas de todos eles nos leva a compreendermos que se trata também de um desabafo que por muitas vezes encontra-se marcado por dificuldades e lamentos.

\subsection{O que dizem os professores sobre a indisciplina na escola e em sala de aula?}

A primeira pergunta contida no questionário: $O$ que dizem os professores sobre o significado da indisciplina? Tendo como respostas seguintes mostram suas concepções acerca do que entendem:

Professor 1: "Comportamento e atitudes do aluno que prejudica ele e os outros durante a aula".

Professor 2: "Indisciplina é a negação da disciplina, a falta de limites, de regras, negação das normas, mal comportamento que compromete as vivências sociais".

Professor 3: "Falta de limites dos alunos, bagunça, tumultos, mau comportamentos, desinteresse e desrespeito".

Professor 4: "Falta de respeito as regras, que não tem um bom comportamento".

Professor 5: "É quando o aluno não cumpre suas obrigações escolares, mal comportamento, falta de respeito com colegas e professores". 
Professor 6: "Falta de respeito as regras da escola, mal comportamento que compromete a convivência em sala de aula".

Professor 7: "São comportamentos abusivos e intensos que acabam dificultando o ensino, aprendizagem e frustrando todos envolvidos nesse processo".

Professor 8: "Indisciplina é quando o aluno procura de toda maneira atrapalhar o trabalho interferindo na aprendizagem deles e dos demais".

Professor 9: "Falta de disciplina, desobediência, insubordinação, rebeldia".

Professor 10: "Falta de interesse do aluno".

Parrat-Dayan (2008) complementa a seguir essas compreensões de que é complicado imaginar uma escola sem disciplina, sem regras e/ou normas. $E$ diz o seguinte:

\begin{abstract}
A disciplina consiste num dispositivo e num conjunto de regras de condutas destinadas a garantir diferentes atividades num lugar de ensino; A disciplina não é um conceito negativo; ela permite, autoriza, facilita, possibilita. A disciplina permite entrar na cultura da responsabilidade e compreender que as nossas ações têm consequências (PARRAT-DAYAN, 2008, p.8).
\end{abstract}

Então, o aluno disciplinado ao contrário do indisciplinado, obedece cegamente às regras escolares, como também se comporta plenamente, de forma consciente de forma que construa uma vivência social sem frustações.

Sobre essas primeiras conceituações acerca da indisciplina, os professores conceituaram através das próprias vivências, ao invés de pesquisar conceitos já prontos e, isso foi bem importante pra pesquisa porque já é uma relação com a prática diária.

Nesse aspecto, o conceito de disciplina encontra-se relacionado com as regras e obediências; e indisciplina é o contrário, a desobediência e essa regra.

Seguindo a pesquisa, a segunda questão, teve como objetivo conhecer se a indisciplina escolar interfere no processo de ensino-aprendizagem do aluno e, assim, todos os professores participantes disseram em suas respostas que afetam sim diretamente.

A partir dessa confirmação de que a indisciplina interfere na aprendizagem e no ensino, fica claro, que o ambiente escolar é um espaço de 
aprendizagem em que o aluno desenvolve as suas várias habilidades e, por conseguinte, consegue desenvolver os saberes que foram adquiridos durante as aulas e, assim poder usar essas aprendizagens socialmente no mundo em que vive. $\mathrm{E}$, para isso acontecer, é necessário que o aluno tenha compromisso, domine, e aplique durante toda a sua vida de forma humana e disciplinada.

É possível que a causa desse processo indisciplinado seja também originado em razão do aluno não saber os motivos pelos quais ele precisa está na escola, é o que afirma o autor Eccheli (2008):

É provável que a indisciplina observada nas escolas esteja diretamente relacionada à falta de motivação dos alunos diante do fato de se verem obrigados a estar numa sala de aula sem entender o porquê e para quê daquilo, considerando os conteúdos inúteis ou, mesmo que sejam úteis, não compreendendo bem para que servem (ECCHELI, 2008 p. 210).

Tomando por base esse entendimento, os professores então responderam na terceira questão em sua grande maioria que a indisciplina interfere na vida escolar do aluno, enquanto que houve dois professores que disseram que não interfere e, isso vai da concepção e compreensão de cada um deles naquele momento.

A educação é muito mais que transmitir conhecimentos, é fazer com que o aluno construa a sua própria aprendizagem e, para isso precisa ter a convicção do que ele precisa realmente se está em uma escola como disciplinado ou se é continuar indisciplinado.

Nesta perspectiva, a postura do professor deve ser de acordo com a realidade dos alunos e, se de seus comportamentos, sempre valorizando e respeitando cada um deles. Além disso, o professor também precisa analisar as suas próprias atitudes.

Corroborando os autores abaixo diz:

[...] é preciso chamar a atenção, mas sempre com respeito e mostrando que o grupo é que está sendo prejudicado, e não apenas você, pessoalmente. Tratar o estudante dessa forma faz com que ele também perceba como agir em momentos de conflito (MOÇO; GURGEL, 2009, p. 36). 
Então o professor tem que pensar nessas várias possibilidades em pensar como intervir no enfrentamento da indisciplina escolar e, também ir sempre à busca de novas iniciativas que perceber que podem melhorar a situação.

Compreende que muitos professores dizem sobre o problema da indisciplina escolar é algo que vem da sociedade, por exemplo, ou seja, de fora para dentro dos espaços escolares. Já outros acham que pode ser psicológico e, assim deve procurar um profissional especialista para estudar o caso.

Ao final de todas as questões, fica claro que a escola em partes não se atenta muito aos problemas, ou seja, deveriam levar mais a sério já que é algo bastante presente. A formação é algo relevante porque prepara o professor e, que muitas vezes não sabe agir devido à falta de preparação.

Ao final da realização dessa pesquisa e a partir de sua análise, percebese que a indisciplina escolar é algo bastante presente no cotidiano escolar e, isso como foi relatado por muitos deles afeta bastante o processo de aprendizagem tanto dos alunos como a prática do professor em sala de aula.

Todas as respostas mostraram que o tema do estudo é realmente bem desafiador, complexo no que se refere aos professores que não recebem nenhum tipo de formação para seu enfrentamento e, assim trabalha em um ambiente bem problemático.

Com os estudos teóricos e a realização da pesquisa foi possível aproximar o que antes entendia apenas teoricamente e, visto como isso é na realidade através de alguns fatos esclarecidos.

Esses profissionais da educação pesquisados assim como os demais outros são importantes para o enfrentamento da indisciplina escolar, talvez seja os mais responsáveis em razão de estarem ali convivendo todos os dias com os seus alunos.

Mas para isso, o professor tem que compreender o seu papel e sua prática de ontem e, de hoje, para assim pensar uma nova prática de amanhã que venha a estabelecer mudanças significativas. Pois, a indisciplina escolar é algo bem antigo e que perpetua fortemente nos dias atuais também e, é por esse motivo que deve ser prevenido e combatido. 


\section{CONSIDERAÇÕES FINAIS}

Ao final dos estudos, pode ser feitas algumas reflexões como saber a razão pelo qual os professores e todos os países civilizados estão se dedicando horas e horas de seu tempo para pensarem sobre a indisciplina escolar.

Já que existem tantas outras questões para serem discutidas como currículo, métodos de ensino, avaliação, enfim, por qual motivo estão se dedicando tanto tempo a esse fato indisciplinar.

Existem inúmeras razões e, uma delas talvez seja que o conteúdo não esteja claro em pleno século XXI. Afinal qual é a disciplina que faz sentido em nossas escolas nos dias atuais, para os professores e alunos.

A partir dessas reflexões, este artigo se tornou um convite para que todos os professores reflitam sobre a indisciplina escolar. Ao que foi constatado ao longo de todo esse trabalho, ficou claro que a indisciplina é algo ligado à falta de respeito, de cooperação, de convívio social.

Antes de tudo isso, é necessário compreender também que o público de alunos hoje nas escolas é caracterizado pela imperatividade. Isso porque os alunos tem acesso a várias formas de comunicação e, com isso, gera a dificuldade em muitas das vezes de ter o foco, claro que existem inúmeras outras razões para a indisciplina escolar.

A indisciplina se torna evidenciada na relação também do aluno com o seu colega de sala, pois o desrespeito também é responsável pela sua originalidade.

Claro que durante a fala de alguns professores citado logo acima mostraram que os pais muitas das vezes encontram-se desagarrados de seus filhos, não impondo limites e princípios básicos como saber respeitar o próximo seja quem for saber ouvir e saber falar tudo no seu tempo, etc.

Outros comentários ditos pelos professores também se firma no aspecto de que a solução está na família de cumprir com o seu papel, de impor limites aos seus filhos, pois o costume vem de casa e procede na escola. Ficou claro que a família tem papel fundamental na formação de seus filhos, para que este se torne bem comportado e um cidadão civilizado. 


\section{REFERÊNCIAS}

AQUINO, Julio Groppa. Da (contra) normatividade do cotidiano escolar: problematizando discursos sobre a indisciplina discente. Cadernos de Pesquisa, São Paulo, v. 41, n. 143, p.456-484, maio/ago. 2011.

AQUINO, Júlio. (Org)- Indisciplina na escola: alternativas teóricas e práticas. 2.ed; São Paulo: Summus, 1999.

ECCHELI. S. D; A motivação como prevenção da indisciplina. Educar, Curitiba, n. 32, p. 199-213, 2008. Editora UFPR Disponível em: http://www.scielo.br/pdf/er/n32/n32a14. Acesso em: 12 de jan. 2019.

FERREIRA, A. B. H. Dicionário Aurélio. 7. Ed. Curitiba: Positivo, 2008.

GARCIA, Joe. Indisciplina na Escola: uma reflexão sobre a dimensão preventiva. Curitiba Ipardes. 1999.

PARRAT-DAYAN, Sílvia. Trad. Sílvia Beatriz Adoue e Augusto Juncal. Como enfrentar a indisciplina na escola. São Paulo: Contexto, 2008.

VASCONCELOS C. dos Santos. Para onde vai o Professor? Resgate do professor como sujeito de transformação. 10. Ed. São Paulo: Libertad, 1996. 